\title{
Dewatering techniques in conservation the antique situation
}

Keywords: deterioration, demolition, reconstruction, convenient length, facint technique, soil stabilization

\section{Introduction}

Our old invaluable monuments and how much they represent as a human and cultural heritage by the factors of carelesness, depreciation, deterioration, demolition, and new constructions in the vicinity of the monuments. Those constructions may not be architecturally compatible with each other's. Along with sustainable improvement from different affairs regarding the monuments and what international treaties and conferences states that the rehabilitation process must clarify the artistic and historical value for the antique and depends on respecting the original documents so as to be distinct from the original state, and represents the slogan of its era. Also, the restoration process must be accurate and out of a rigorous well detailed study. The restoration must terminate when the work begin to alter the original state.

New material and techniques must be used in the restoration and reinforcement process of the antiques. So far we find that the academic research and new techniques is the sole support in which the restoration and conservation process may result. So we see that it is a must to study the Dewatering techniques and methodologies that leads to conservation of the antiques.

\section{Classifaction of the interfering types for conservation of the historical buildings}

Methodologies and techniques used to preserve antiques: The techniques and tactics used in conserving antiques differ from an antique to another. This wide variation depends upon antique status, age, and how much this antique needs reforming and rehabilitation to preserve its original status. Those methodologies or patterns can be summarized as follows:

a. Preservation.

b. Conservation and rehabilitation.

c. Restoration.

d. Integration and reservation of old parts

e. Recreating the antique in non-monumental parts.

f. Reconstruction and fitting works.

g. Rebuilding demolished parts of the antique.

The completion of the issue under research may need one or more of the previously mentioned factors. Here in those methodologies in more details will be discussed. ${ }^{1-8}$

a. Preservation: Some parts of the antique that have not been yet under demolition, and still, to some extent, have its old form and status. Those parts could be maintained and re-stabilized structurally to facilitate maintenance works in other parts. This can be accomplished by sustainable allocation of different parts
Volume 2 Issue I - 2017

Hossam Eldin Elborambaly,' Ayman Elsayed
'Department of Civil Engineering, Ain Shams University, Egypt

${ }^{2}$ Architectural Department, Ain Shams University, Egypt

Correspondence: Ayman Elsayed, Department of Civil Engineering, Ain Shams University, Egypt, Tel +2 01001010552 , Email dr_aymanz@yahoo.com

Received: December 07, 2016 | Published:January 27, 2017

of the structure. Precise surveying works such as coordinates tracking and leveling may be the tool to judge status variability of the monument.

b. Conservation: It is a periodical process in which failures occurring in some parts of the structure will be cured and rehabilitated to maintain and elongate life time of the antique. This methodology will succeed through accurate maintenance plans that may ban failures at all Figure 1.

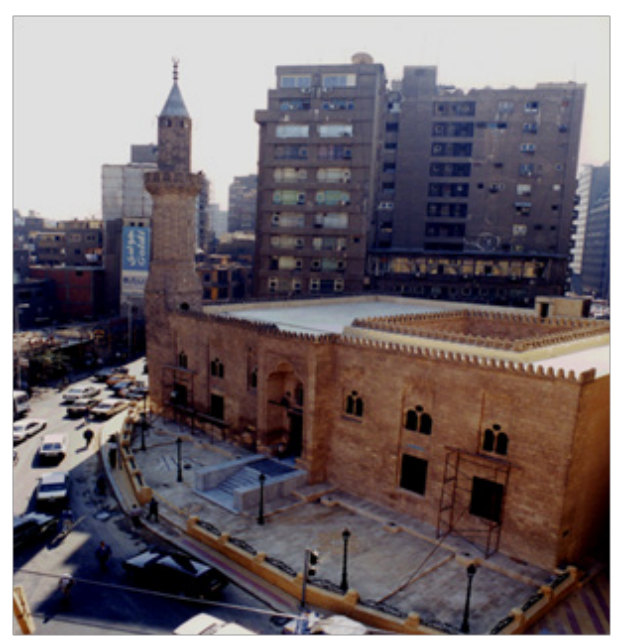

Figure I Kekhya mosque in Opera square in Cairo, it is clear the addition of the fence.

- Maintenance procedures are done through

I. Deterioration remediation one by one.

II. Periodical check up for all antique parts and associative elements that serve conserving the antique.

c. Restoration: It is the restoration of the antique status into its original status or as soon of which as possible. Actually, remediation and maintenance procedures do differ from antique to another Figure 2-7.

d. Integration: is the process of completing lost fragments by integrating the visual appearance of buildings. This can be accomplished by tracing works previously recorded before antique partial or local failures. The tracing may be 
photographical, architectural, or geodetically*. The tracing process may be done to identify the original shape of the antique and materials used to construct it.

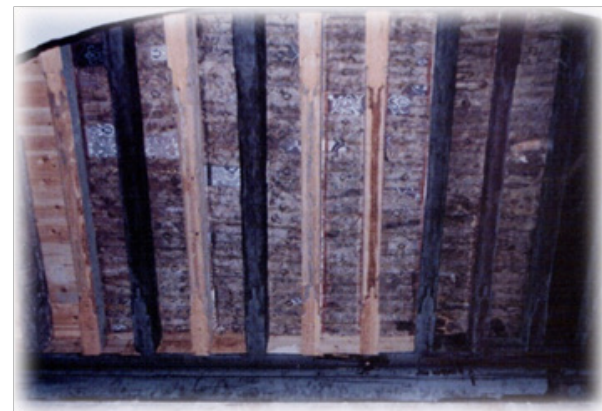

Figure 2 An image clarifies the deterioration and depletion of the tramps in the northern west shrine of El-Dashtoshy mosque, Port Said Street, Cairo.

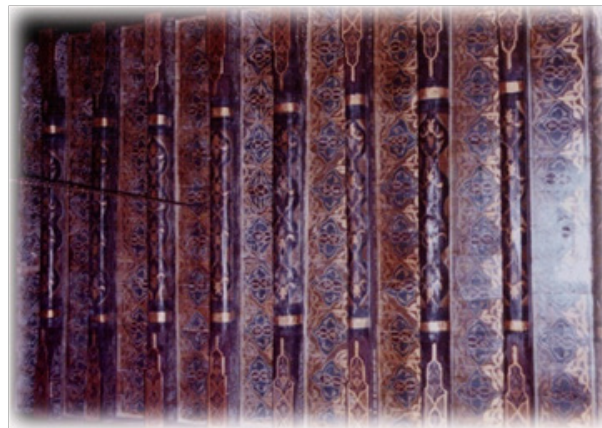

Figure 3 An image clarifies the tramps in the northern west shrine of ElDashtoshy mosque after complete and precise conservation.

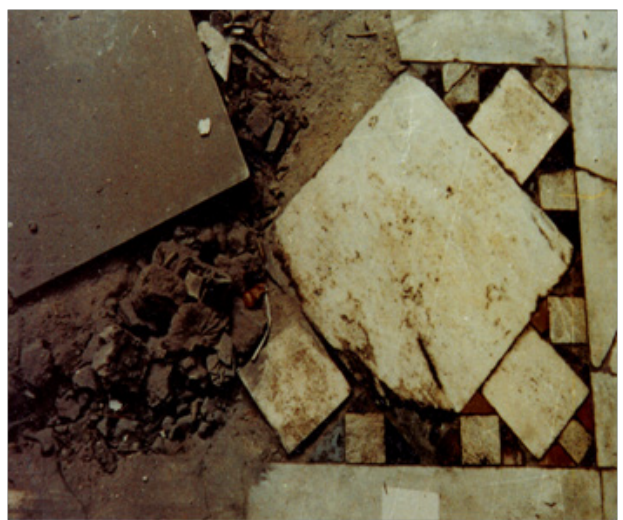

Figure 4 Architectural conservation works-deterioration of scrap marble for some flooring units, El- Kekhya mosque, Opera square, Cairo before conservation.

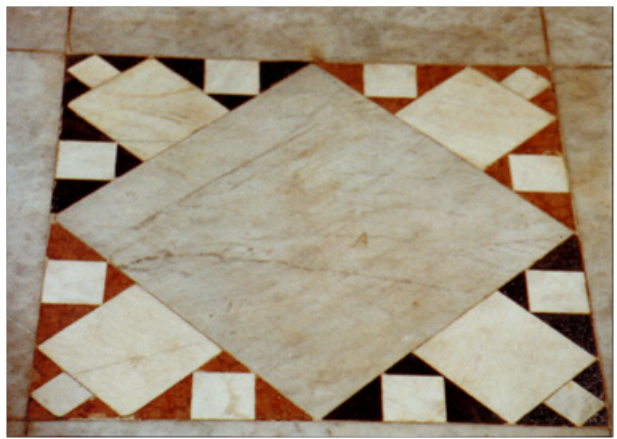

Figure 5 Architectural conservation works-deterioration of scrap marble for some flooring units, El-Kekhya mosque, Opera square, Cairo (after conservation).

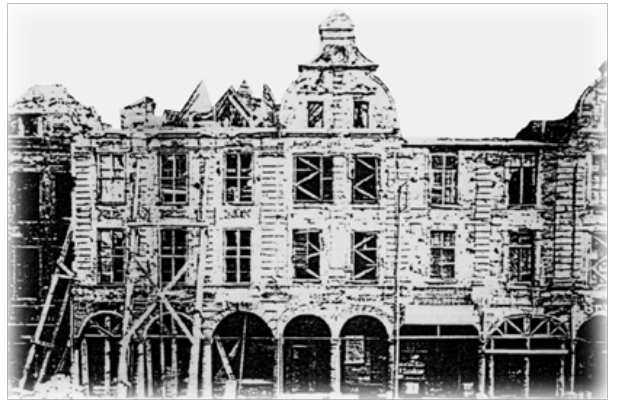

Figure 6 Main square in Paris before restoration and conservation. Courtesy of Sepedem- photographer.

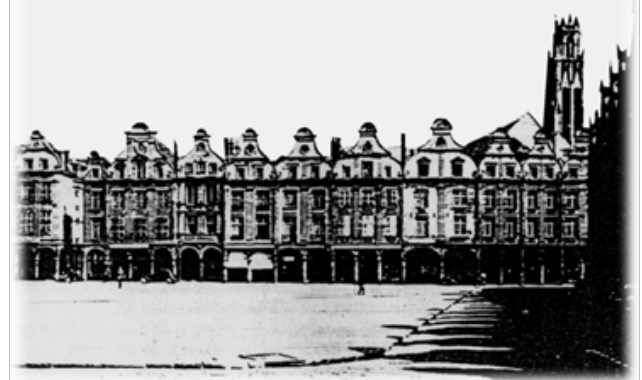

Figure 7 Main Square in Paris after restoration and conservation. Courtesy of Sepedem- photographer.

\section{- Procedures used in integration:}

I. Assembling all previous studies and architectural or photographical tracing tasks for precise identification and distinct structural pattern of the antique.

II. Completion of the monumental studies and structural analysis and modeling needed to distinguish the original construction process and original material used in construction Figures 8 \& 9.

III. Architectural documentation and registration for antique present status.

IV. Photographical and video film monitoring of the recent antique status.

V. Proposal of the appropriate design to integrate the antique, also structural supporting system proposed.

VI. It must be noted that by any mean the completed nonoriginal parts must be distinguished apart from the original antique status.

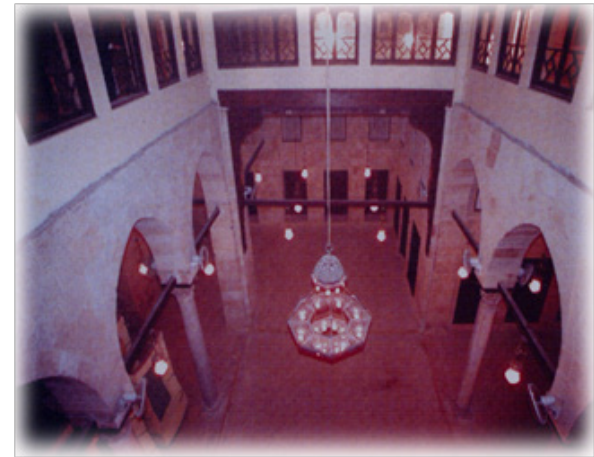

Figure 8 Complementary works and shrines illumination in El -Dashtoshy mosque. 


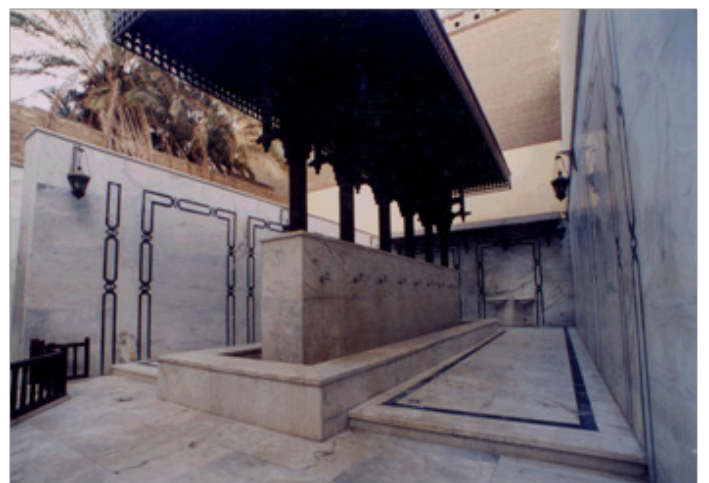

Figure 9 Complementary works- sanitary works.

e. Recreation: This includes removing and discarding intruding elements that have been fabricated in recent durations and have no definite artistic value.

\section{- Procedures and methodologies used in recreation}

I. Assembling all previous studies and architectural or photographical tracing tasks for precise identification and distinct structural pattern of the antique.

II. Architectural and photographical registration of the antique recent status.

III. Determination of the non-monumental parts of the antique needed to be recreated.

IV. Recreation is done in a manner that guarantees safety and workability of the antique.

V. Architectural and surveying registration of the antique and non-monumental parts of the antique.

\section{f. Reconstruction}

Those procedures are needed when it becomes impossible to maintain the antique by conventional methodologies.

Procedures and methodologies used in reconstruction:

I. Assembling all previous studies and architectural or photographical tracing tasks for precise identification and distinct structural pattern of the antique.

II. Un-fitting of the parts that can be attached and assembled together after maintenance completion.

III. Structural maintenance of the antique.

IV. Soil stabilization and foundation support.

V. Reconstructing the antique to restore its original status before un-fitting of the antique.

g. Rebuilding: It is the reconstruction of antique part that recently does not exist, or displacement of the original parts of the antique into a new location.

\section{- Procedures and methodologies used in rebuilding}

I. Assembling all previous studies and architectural or photographical tracing tasks for precise identification and distinct structural pattern of the antique.

II. Photographical and surveying registration of the antique.
III. Preparation of working or shop drawings that will maintain the reservation of the original status of the antique.

IV. Reconstruction works provided that combination of variety of required specialties and public care.

V. Registration and recording of architectural history of the building.

This phase contain registration of all interior and exterior antique parts by photography using variety of digital or video cameras. The parts needed to be registered should be captured horizontally and vertically. Also, frame of each capture and number must be recorded. Photograph elevation and altitude must be recorded in a tabular form.

- Photographical registration for entrances: First of all, entrance must be divided into set of partitions, horizontally and vertically. Provided that these images must be numbered and camera point and altitude must be recorded Figure 10.

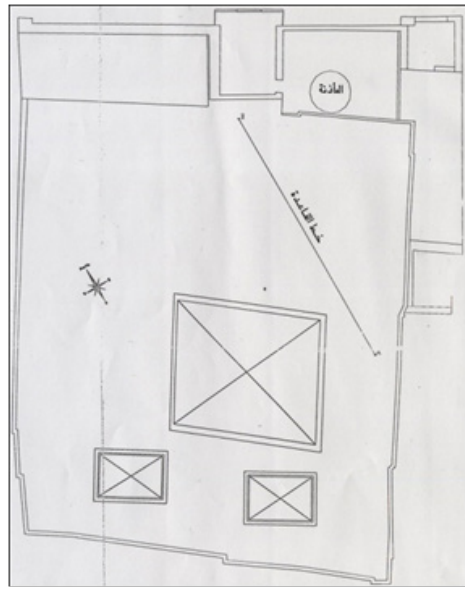

DISPLACENENT OF MINERATE BETWEEN SEC $1-1 \nless 2-2$

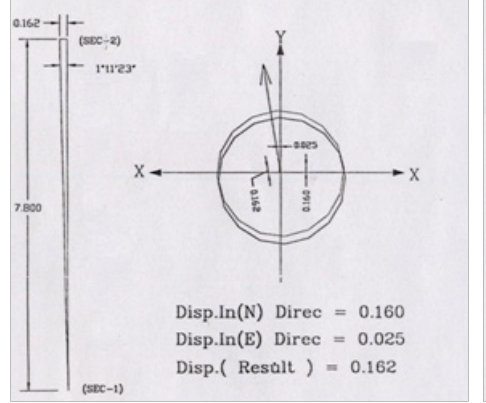

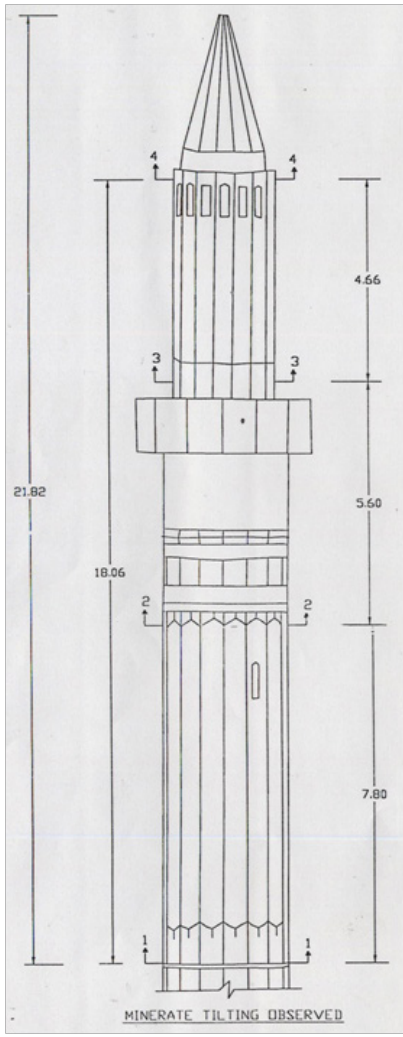

Figure 10 Plan and elevation of El- Fakahany mosque minaret in Cairo and tracing model of the minaret at different levels).

- Determination of Structural techniques for modelling the antique

1. Dewatering process and their unexpected effects: Ground water threatens antiques foundation by affecting material, soil leaching, bearing capacity failure, and capillary action. For which sustainable ground water lowering must be maintained, this can be summarized as following steps:

a. Drainage wells must be placed around the monument circumference at an appropriate depth.

b. Bottom part must be perforated to a convenient length and zigzag pattern is preferred. 
c. Wells are interconnected by two drainage lines at end of which lies pumps that convey such a ground water to the nearest sewerage network.

d. The drainage network should be maintained and stand by pumps must coexist Figures $11 \& 12$.

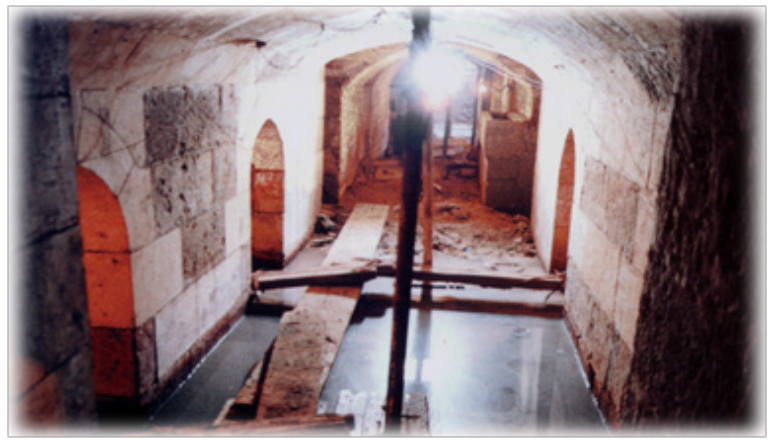

Figure I I Ground water elevation in basement corridor in El-Dashtoodhy Mosque-Port Said.

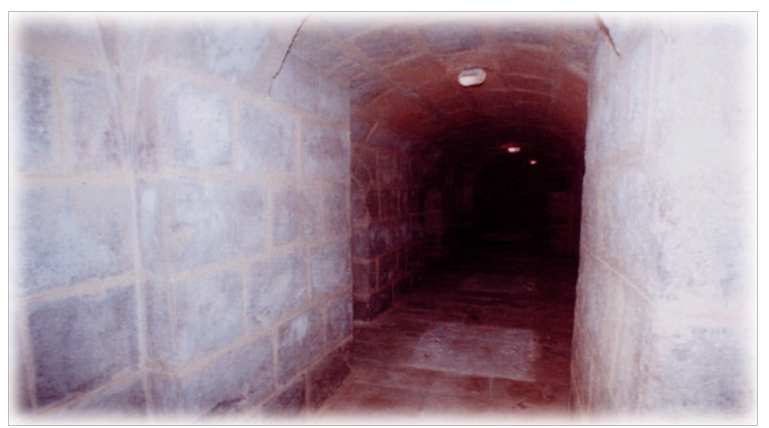

Figure 12 Ground water elevation in basement corridor in El-Dashtoodhy Mosque-Port Said After maintenance.

\section{- Consolidation process}

In some cases walls and some structural elements need more strengthen and reforming for some salts polymerization resulting in some local failures in walls media. Some global conditions must exist in the consolidation chemicals:

This chemical must not result in chemicals or harming byproducts. Easy application and preservation of original colour.

Consolidation chemical should have the ability of penetrating surfaces smoothly and with small viscosity.

There are lot of consolidating agents, organic and inorganic. Most of inorganic agents result in insoluble chemicals. But alas, some inorganic chemicals made excessive and rapid failures because of induce pore pressures due to the byproducts and chemicals. Hence organic chemicals are most preferred and hereby some of organic cosoldates:

Most organics are synthetic high molecular weight particles results from polymerization of their constituting molecules which termed as "Monomers". Those consolidate are divided into main distinct groups:

I. Thermo Plastic Resins: which are high organic compounds that soften with heat and solidate with cooling. Venyles are most common compounds used in which.

II. Thermo Setting Resins: Organic compounds harden with heat and divide into two main groups.
III. First of which are monomers that mix with hardener in room ordinary temperature. The resulting resin will not soften with heating, also the resin become insoluble.

IV. Second are in the form of cobbles of soft media which molecularly have a cross links. Some common kinds of which are Phenols and Phormaldehydes resins.

V. Some common and well reputable material in cracks curing and filling are Epoxies and Polyesters and Silicon.

\section{- Techniques used in surface curing}

a. Continuous flow: Paper Facint Technique is widely used to cover walls by cellulosic papers and laminas using Phenyle alcohol as a binder. Consolidate reservoir is placed above the wall and connected to the paper that saturates with the consolidate and convey the substance to the wall. A PVC shield is used to cover the paper to prevent excessive evaporation of the consolidate. Some defect of this method that the paper remain wet long time may last two hours, which may cause lot of losses in consolidate material.

b. Squeeze Bottle: small bottles made from resigns that have the ability to be compressed and restore their original size by ejecting the consolidate inside them. Those bottles are scattered horizontally and vertically on wooden logs and compressed, hence they squeeze their cosolidate content into wall media This method has less waste in cosolidate material.

\section{- Bricks and wall boulders maintenance}

The most effective and hazardous agent is cracks and deep fissures. Those cracks result from either severs weathering circumstances or structural faults in foundation or in sub soil. A part from aesthetic displeasing impression. Details of cracks curing is summarized below,

\section{- Deep and wide cracks}

Defected bricks and boulders must be replaced with new ones. Certain steps must be followed,

I. Ceiling and floors must be structurally isolated to stand alone. Steel ties and struts are used to transfer such loads into ground without loading upon defected walls.

II. Precise determination of the defected area.

III. Wall furnishing is removed.

IV. Boulders are detached from the wall media at a depth of minimum $50 \mathrm{~cm}$ and width $100 \mathrm{~cm}$ around the crack area.

V. Wall sides are cleaned by compressed air.

VI. Steel bars 6 or $8 \mathrm{~mm}$ diameter are fixed into walls sides around the detached boulders at about $40 \mathrm{~cm}$ spacing. Mechanical drilling is used to fix such bars at a depth of $10 \mathrm{~cm}$ and epoxies are used to bind them.

VII. Special binding mortar is used to bind new boulders into walls media.

VIII. Finally some small voids may result so mortar or small newly fabricated bricks may be used.

\section{- Moderate cracks curing}

Cracks from boulders buffers and irregular bricks may be of moderate depth. Those cracks can be overcome by insertion of non- 
corrodible bars inserted to a depth of $5-7 \mathrm{~cm}$ inside the boulders. Those bars are binded by epoxies at their ends. The spacing between successive bars are from 40 to $60 \mathrm{~cm}$. Steel mesh is placed at the wall side. The mesh extends $15 \mathrm{~cm}$ from crack area on both directions. As for horizontal cracks steel meshes are fixed above and beneath those cracks at $10 \mathrm{~cm}$ distance.

The special methods for supporting the foundation and the soil consolidation:

a. Foundation supporting and soil stabilization: Soil stabilization is a tickling issue as soil must be maintained at strength that conserves foundation and facilitate digging during foundation maintenance there are many methods one of which is electric method.

b. Soil Strengthing by electric current: Ground water entrained within soil pores possesses positive charges while pores walls have negative charges. A forced electric current is superimposed within soil media water seeps away from Anode and flow towards Cathode, hence soil in Anode vicinity stabilizes and water around Cathode is pumped out. Moreover $\mathrm{Fe}^{+3}$ and $\mathrm{Al}^{+3}$ from Anode rods penetrates soil and bring it more stabilized.

\section{- Soil stabilization by injection}

a. In case of weak superstructure this method proved potent and it steps as follows:

b. Soil beneath foundation is injected by salts free cement mortar.

c. Injection pressure mustn't be high but moderate pressure is preferable.

d. Injected portion must exceed twice foundation depth.

e. Superstructure fissures should be filled with binding material.

f. Injection material isolates footing from inert aggressive soil material.

\section{- Soil Stabilization by micro piles}

Piles with diameter $100-150 \mathrm{~mm}$ are placed beneath the footing to transfer load to sub soil with working loads 15-60tons. Plies depend upon friction, certain precautions must be followed:

I. Convenient structural design for piles material and reinforcement Figures $13 \& 14$

II. Ensure buckling resistance and ensure cohesion between piles, surrounding soils andical isolation for foundation used in historical building.

a. Isolation processes: Superstructure must be isolated against aggressive ground water chemicals. This is attained by comprehensive physical, chemical isolation techniques:

b. Physical isolation: PVC laminas are inserted at a convenient height from ground to block humidity. So called "Chain saw" is used to form laminas to prevent excessive vibration. Also, bituminous or lead laminas or even resins mortar is used to bind PVC shells within bricks.

c. Chemical isolation: Water repulsing material like polyester and silicon which have the following merits.

III. Good binding characteristics

IV. Light resistance,

\section{High liquidity and permeability,}

VI. Resists aggressive chemicals in the vicinity,

VII. Does not cause occlusion of surface pores in the bricks.
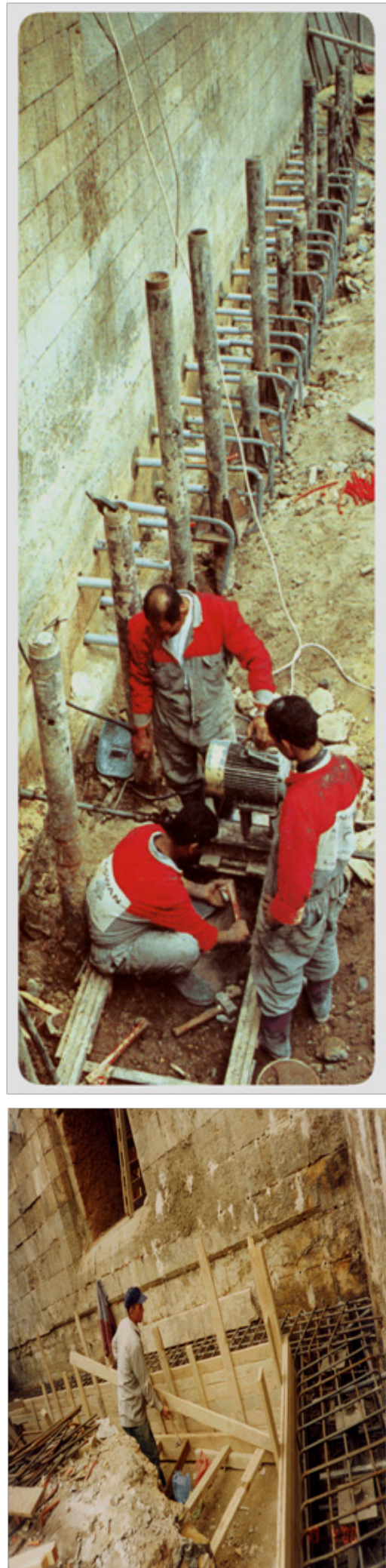

Figure I 3 Soil stabilization process in El-Kekhya Mosque. 


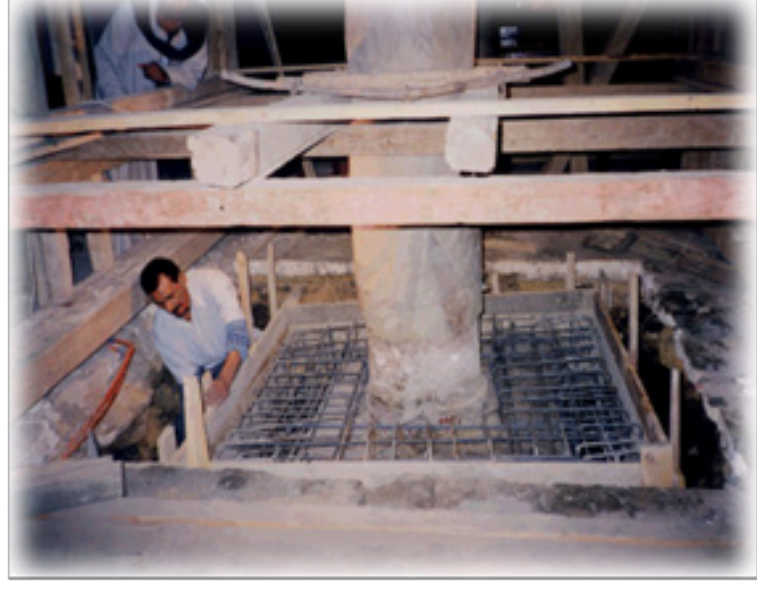

Figure I 4 Soil stabilization and footing support in El-Azra church.

Injection process is done by inserting a set of micro pipes into walls bulk and pumping the isolating chemical into which under pressure. Pipes are formed with a spacing of $15-17 \mathrm{~cm}$. Thick walls is injected from their both sides Figure 15.

a. Cleaning and salts elimination: Is an aesthetical process to remove salts and strange material from antique surface as follows

b. Cleaning: Meant by which dust, salts, and patches from antique surface. Cleaning is mechanical and chemical.

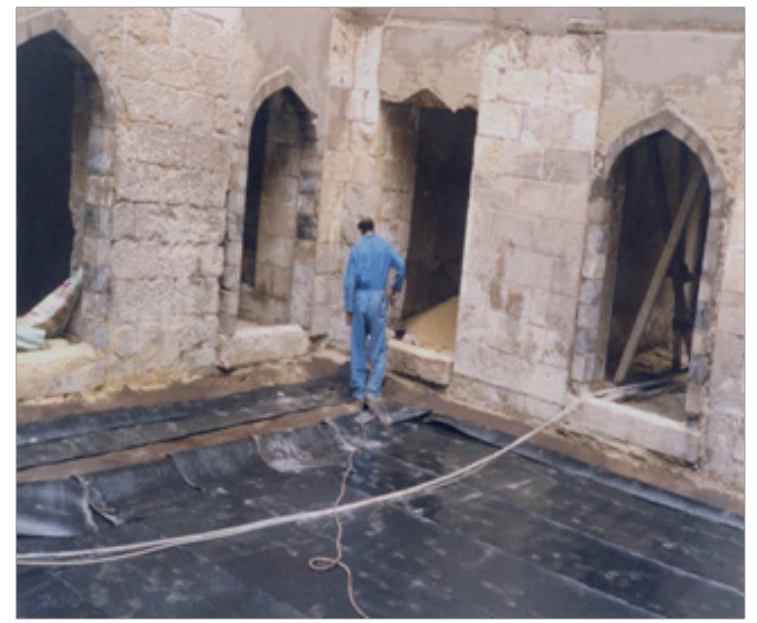

Figure 15 Floor isolation process in Sarghatmash mosque-El Saleeba Cairo.

\section{Mechanical cleaning}

Salts are removed mechanically by means of fine and coarse brushes provided that marble and precious stones remains scratches free. Some hand carried apparatus that have Carborundum blades or sand stone heads with water and lubricants. Also blasting dry drift technique is used to gush dirts off by flushing particulates and compressed air. This technique require 4 s high caution and Bauxite particulates and small fabrics may be used instead of sand grains as warring grains. Wet grit blasting is used when salts effect is not the cause of surface defects.

\section{Chemical cleaning}

Test are about $5 \mathrm{~cm}^{2}$ is used to test the chemical effects on the brick media. First step must be pure water cleaning to remove dirt and dust, warm water with soap may prove more effective. Practical experience showed that $100 \mathrm{~cm}^{3}$ distilled water $+10 \mathrm{gm}$ neutral soap $+1 \mathrm{~cm}^{3}$ Ammonia solution proved potent in cleaning process Figure 16.
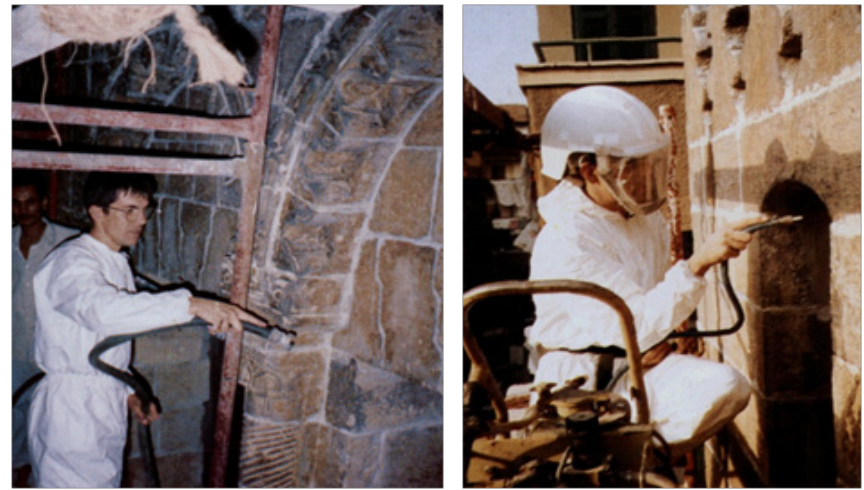

Figure 16 Mechanical cleaning in Abdelrahman Katkhoda mosque-E Megharbeleen Cairo.

\section{Silt mortar}

Attapulgite and Sepiolite are two potent minerals for marble surface cleaning. Those silt minerals have the ability to clean and polish marble surface. Polyethylene is used to pre cover the surface before silt mortar curing.

\section{High Technology for fine restoration in dealing with the Antique}

The fine restoration process is accomplished according to predetermined methodology which includes precise study of the restoration portions and how much they defected are. First of all those portions are traced then specimens are prepared. Then, evaluation tests are performed upon those samples. According to those tests' outputs and the analysis of the antique material the restoration methodology can be selected. The methodology contains best knowledge of defects sources, hazards, and restoration process. Restoration process includes all antique elements, i.e. bricks, wood, etc. Bricks are inspected against weathering, or saline water. Wood, glass, paintings, and wallpapers are inspected by $\mathrm{X}$ ray to determine the molecular composition of each. Also some physical and mechanical tests may be conducted to supports previous tests outputs. Trappings and housings are very common in antiques. Their inspection process is performed by; first, preparing comprehensive sketches for the trappings, then the defected parts are determined and compensated by the same material and color. The initial pattern and shape must be restored, provided the use of adequate material that superior performance. Architectural analysis of the design sheets and restoration process are essential to maintain the same historical pattern of the antique, also to guarantee no intruding additions or omitting necessary parts.

\section{Methods used in the integration of the historical buildings}

Restoration process, as a rule of thumb, must be executed using similar material to those of the antique initial state. To achieve such a goal it is recommended to permit more time to the specimen inspection. Moreover, precise inspection and testing may give a cursor towards defects source, which may be aggressive chemicals or saline water.., etc. In such a case detailed architectural drawings and schematics will be the sole guide to restore lost and defected fragments, which lead to restore antique initial state at the end. In this paper multiple examples and case studies are used to clarify restoration process. 


\section{Conclusion}

Through the study of the factors that affect conservation of antiques we can summarize them as follows:

Natural and environmental parameters.

It is considered the most affecting parameter to the building and its content its huge influence comes from the difficulty of controlling or predicting as

I. Under ground water: Which is considered the first problem in most of Egyptian antiques, especially those integrated with the urban mass of the city.

II. Natural disasters: Shakes which take place in ground or in the water or earthquakes and overflows.

\section{Social human parameters}

Which are the resultants of the humans dealing with the antique building is the urban surrounding it. And what makes it negatively affecting the antique is the leakage of antique realization in the surrounding society and the negative effects are:

a. Infringements on antique, which affect most of historical monuments in Cairo.

b. The misues of historical buildings integrated with the urban mass of the city especially those with no use.

c. To overcome such negatives we must increase antique realization of the society as a whole and the surrounding the antique area as special.

\section{Urban and technological parameterers}

The kind and size of the negatives caused by this parameter depends on the kind and phenomena of urban society surrounding the antique a. Infra structure required serving the antique.

b. Matching the new building style with the style of the antique area.

c. Using mechanisms in all fields leads to vibrations and noises, which negatively affect the antique building.

\section{Acknowledgements}

None.

\section{Conflict of interest}

The author declares no conflict of interest.

\section{References}

1. Council of Europe. Preservation and rehabitation of the cultural heritage of monument and sites. Strasbourg; 1970. p. 19-85.

2. What is our hertage? United Kingdom Archievements for European Architectural heritage. Department of the Environment. 1975:135.

3. Francois Sorline, Europe: The comprehensive effort. The conservation of cities UNESCO press Paris; 1975.

4. Heritage Trust conservation and tourism: second international congress on architectural conservation and town planning. 1975.

5. Ismail Adel A. The physical-Environmental Characteristics of the Islamic Arabcity master of urban planning Thesis. USA: university of Washington; 1965

6. Issawi Charles. Egypt: An Economic and social analysis. USA: Oxford University Press; 1947.

7. Lawless RI, Arunacalam AM. Problems and planning in the third world cities by Michael pacione.

8. Tilley Roger. Conservation in Action in Chester. Built Environment. 1973:96. 